\title{
Endocannabinoids in Chronic Migraine: CSF Findings Suggest a System Failure
}

\author{
Paola Sarchielli*,', Luigi Alberto Pini' ${ }^{2}$, Francesca Coppola', Cristiana Rossi', Antonio Baldi ${ }^{2,3}$, \\ Maria Luisa Mancini' and Paolo Calabresi ${ }^{2,3}$ \\ 'Neurologic Clinic, Department of Medical and Surgical Specialties and Public Health, University of Perugia, Perugia, Italy; ${ }^{2}$ Department of \\ Biomedical Sciences, Headache Study Center, Institute of Toxicology and Clinical Pharmacology, University of Modena and Reggio Emilia, \\ Modena, Italy; ${ }^{3}$ RCCS, Fondazione Santa Lucia, Rome, Italy
}

Based on experimental evidence of the antinociceptive action of endocannabinoids and their role in the modulation of trigeminovascular system activation, we hypothesized that the endocannabinoid system may be dysfunctional in chronic migraine (CM). We examined whether the concentrations of $\mathrm{N}$-arachidonoylethanolamide (anandamide, AEA), palmitoylethanolamide (PEA), and 2-arachidonoylglycerol (2-AG) in the CSF of patients with CM and with probable CM and probable analgesic-overuse headache $(\mathrm{PCM}+\mathrm{PAOH})$ are altered compared with control subjects. The above endocannabinoids were measured by high-performance liquid chromatography (HPLC), and quantified by isotope dilution gas-chromatography/mass-spectrometry. Calcitonin gene-related peptide (CGRP) levels were also determined by RIA method and the end products of nitric oxide (NO), the nitrites, by HPLC. CSF concentrations of AEA were significantly lower and those of PEA slightly but significantly higher both in patients with CM and PCM+PAOH than in nonmigraineur controls ( $p<0.01$ and $p<0.02$, respectively). A negative correlation was found between AEA and CGRP levels in CM and PCM + PAOH patients $(r=0.59, p<0.01$ and $r=-0.65, p<0.007$; respectively). A similar trend was observed between this endocannabinoid and nitrite levels. Reduced levels of AEA in the CSF of CM and PCM + PAOH patients may reflect an impairment of the endocannabinoid system in these patients, which may contribute to chronic head pain and seem to be related to increased CGRP and NO production. These findings support the potential role of the cannabinoid (CB) I receptor as a possible therapeutic target in CM. Neuropsychopharmacology (2007) 32, I384- 1390. doi: I0.1038/sj.npp. I 30 I246; published online 22 November 2006

Keywords: endocannabinoids; calcitonin gene-related peptide; nitrites; chronic migraine; analgesic overuse headache; cerebrospinal fluid

\section{INTRODUCTION}

Cannabinoid (CB) receptors and their endogenous ligands constitute a novel modulatory system that is involved in specific brain functions, such as control of movement, memory, neuroendocrine regulation, and also nociception (Howlett et al, 2004).

Several endocannabinoids (endogenous cannabis-like substances), which are small molecules derived from arachidonic acid, have been detected so far: $\mathrm{N}$-arachidonoylethanolamide (anandamide, AEA), 2-arachidonoylglycerol (2-AG) and its ether, the 2-arachidonyl glyceryl ether (noladin ether, NE), palmitoylethanolamide (PEA), $\mathrm{N}$-oleoylethanolamide (OEA), virodhamine (VA), and $\mathrm{N}$ -

\footnotetext{
*Correspondence: Dr P Sarchielli, Neurologic Clinic, Department of Medical and Surgical Specialties and Public Health, University of Perugia, Santa Maria della Misericordia Hospital, Sant'Andrea delle Fratte, 06156 Perugia, Italy, Tel: + 39075578 3609, Fax: + 390755783609 ,

E-mails: neuro.pg@tiscalinet.it; headache@unipg.tt

Received 13 June 2006; revised 7 August 2006; accepted 14 August 2006

Online publication: 26 September 2006 at http://www.acnp.org/ citations/Npp092606060397/default.pdf
}

arachidonoyl-dopamine (NADA). AEA and PEA are the best characterized (Drysdale and Platt, 2003).

Two CB receptor types have been identified in mammalian tissues, the $\mathrm{CB}(1)$ and $\mathrm{CB}(2)$ receptors, which mediate several pharmacological effects of AEA and are primarily localized to the nervous system and immune system, respectively. By being coupled to G-proteins, they can be seen as AEA 'metabotropic' receptors (Di Marzo et al, 2002a, b; Grotenhermen, 2004).

To date, the only reasonably well-characterized, noncannabinoid site of action for AEA is the transient receptor potential vanilloid type 1 (TRPV1), a nonselective cation channel gated also by capsaicin, protons, and heat (Szallasi, 2002; Ross, 2003).

Endocannabinoids are released upon demand from lipid precursors in a receptor-dependent manner and serve as retrograde signaling messengers in GABAergic and glutamatergic synapses, as well as modulators of postsynaptic transmission, interacting with other neurotransmitters, including dopamine (Fride, 2002; Gubellini et al, 2002; Freund et al, 2003; Breivogel et al, 2004; Melis et al, 2004). Endocannabinoids are transported into cells by a specific uptake system and degraded by two well-characterized 
enzymes, fatty acid amide hydrolase (FAAH) and monoacylglycerol lipase (Szallasi, 2002; Grotenhermen, 2004).

A clinical endocannabinoid deficiency (CECD) has been hypothesized to underlie the pathophysiology of migraine, fibromyalgia, irritable bowel syndrome (IBS), and other functional conditions alleviated by clinical cannabis but no clear evidence to support this deficiency has been reported until now in this regard (Russo, 2004).

Migraine, in particular, has numerous relationships to endocannabinoid function. AEA potentiates $5-\mathrm{HT}_{1 \mathrm{~A}}$ and inhibits $5-\mathrm{HT}_{2 \mathrm{~A}}$ receptors supporting a potential therapeutic efficacy in acute antimigraine treatment with triptans, which are specific agonists of $5-\mathrm{HT}_{1 \mathrm{~B} / 1 \mathrm{D}}$ receptors but also exert their agonistic effect on $5-\mathrm{HT}_{1 \mathrm{~A}}$ receptors, and in antimigraine preventive treatment, with particular regard to serotonin antagonists (Kimura et al, 1998; Cheer et al, 1999). CBs also demonstrate antinociceptive and antiinflammatory effects (Calignano et al, 1998, 2001; Hohmann, 2002; Cravatt and Lichtman, 2004; Di Marzo et al, 2002a, b; Pertwee, 2001; Mbvundula et al, 2004). AEA is also tonically active in the periaqueductal gray matter, which is believed to be a putative migraine generator (Vaughan et al, 2000).

Recent experimental findings suggest that AEA, the endogenous ligand of $\mathrm{CB}(1)$ and $\mathrm{CB}(2)$ receptors, is tonically released to play a modulatory role in the trigeminovascular system. AEA seems to act both presynaptically, to prevent CGRP release from trigeminal sensory fibers, and postsynaptically to inhibit the CGRP-induced nitric oxide (NO) release in the smooth muscle of dural arteries. AEA is tonically released to play some form of modulatory role in the trigeminovascular system (Akerman et al, 2004a). All these suggestions prompted us to test the hypothesis that the endogenous $\mathrm{CB}$ system may be dysfunctional in chronic migraine (CM), as in other chronic pain entities such as fibromyalgia and IBS. We therefore examined whether the concentrations of AEA, PEA, and 2-AG in the CSF of CM patients and probable CM and probable analgesic-overuse headache $(\mathrm{PCM}+\mathrm{PAOH})$ patients are altered compared with control subjects and if an association exists between their concentrations and those of CGRP and nitrites, the end products of NO.

\section{PATIENTS AND METHODS}

\section{Patients and Controls}

The study protocol was approved by the Ethics Committee of the Azienda of Umbria and all patients gave their written consent to the study.

Fifteen consecutive patients affected by $\mathrm{CM}$ and 15 patients diagnosed with $\mathrm{PCM}+\mathrm{PAOH}$ according to the criteria of the International Classification of Headache Disorders, ICHD-II (Headache Classification Subcommittee of the International Headache Society, 2004), and attending the Headache Center of the Neurologic Clinic of the University of Perugia were admitted to the study.

The analgesic abused drugs in the $\mathrm{PCM}+\mathrm{PAOH}$ group included nonsteroidal anti-inflammatory drugs, simple or combination analgesics, but not triptans. Combination analgesics included butalbital + propyphenazone + caffeine and indomethacin + prochlorperazine + caffeine. Among the patients with $\mathrm{PCM}+\mathrm{PAOH}$, eight (53.3\%) were predominantly overusing one class of symptomatic medication, four $(26.7 \%)$ were overusing combinations of two or three classes of symptomatic medication, whereas the remaining three $(20.0 \%)$ patients were overusing combination analgesics.

None of the PCM + PAOH patients had opiate abuse or signs of a withdrawal syndrome at the time of assessment.

The monthly drug intake averaged $71.4 \pm 12.6$ (mean \pm SD) tablets or suppositories. None of the patients used drugs containing codeine and/or took preventive medication for at least 1 month from inclusion into the study but they were allowed to take medication for the acute relief of pain.

All patients were admitted to the Neurologic Clinic of the University of Perugia to undergo lumbar puncture.

During their stay in the Hospital, each patient completed a questionnaire consisting of six questions derived from five of seven criteria of DSM-IV substance dependence (American Psychiatric Association, 1994) according to Fuh et al (2005), and the Hospital Anxiety and Depression Scale (HADS), a self-completed questionnaire specifically developed for use in the hospital outpatient setting that yields two subscales: anxiety and depression. According to this scale, clinically significant anxiety and depression were defined as anxiety scores of HADS $\geqslant 8$ and depression scores of $\mathrm{HADS} \geqslant 8$, respectively.

Control CSF specimens were also obtained from 20 agematched subjects who underwent lumbar puncture for diagnostic purposes. In all these subjects, CSF and blood tests excluded CNS or systemic diseases. All control subjects were drug-free for at least 2 months and none of them were taking any medication at the time of CSF sampling or had a personal or family history of migraine or suffered from tension-type headache. None of the above controls developed postlumbar puncture headache. All control subjects were assessed with the same questionnaires administered to patient groups. The details of patients and control subjects are reported in Table 1.

Routine CSF determinations both in patients and controls included total cell count, total protein, measurement of the concentration of albumin and IgG in CSF and serum, determination of oligoclonal bands by isoelectrophocusing, and extensive virological and microbiological testing. Samples were stored at $-80^{\circ} \mathrm{C}$ until analysis.

\section{Methods}

CSF determination of endocannabinoids. This was performed according to the method of Giuffrida and Piomelli (1998) adapted to CSF by Leweke et al (1999) and Giuffrida et al (2004), which involves separation of endocannabinoids by high-performance liquid chromatography (HPLC) and then quantification by gas chromatography/mass spectrometry (GS-MS).

Standards for $\left[{ }^{2} \mathrm{H}_{4}\right] \mathrm{AEA},\left[{ }^{2} \mathrm{H}_{4}\right]$ oleoylethanolamide, and $\left[{ }^{2} \mathrm{H}_{4}\right]$ PEA were synthesized by the reaction of fatty acyl chlorides with unlabeled or $\left[{ }^{2} \mathrm{H}_{4}\right]$ ethanolamine, provided by Cambridge Isotope Laboratories (Andover, MA). $\left[{ }^{2} \mathrm{H}_{8}\right]-2-\mathrm{AG}$ was custom-synthesized by Deva Biotech (Hatboro, PA). Fatty acyl chlorides in dichloromethane $(10 \mathrm{mg} / \mathrm{ml})$ were mixed with one equivalent of ethanolamine, and allowed to react for $15 \mathrm{~min}$ at $0-4^{\circ} \mathrm{C}$. Reactions were stopped by adding 
Table I Details of Patients and Control Subjects

\begin{tabular}{lccc}
\hline & $\begin{array}{c}\text { CM } \\
\text { patients }\end{array}$ & $\begin{array}{c}\text { PCM+PAOH } \\
\text { patients }\end{array}$ & Controls \\
\hline Number & 15 & 15 & 20 \\
Males & $n=4$ & $n=2$ & $n=7$ \\
Females & $n=11$ & $n=13$ & $n=13$ \\
Age (years) & $37.4 \pm 4.9$ & $40.1 \pm 5.4$ & $36.3 \pm 7.4$ \\
Duration of chronic pain (years) & $11.2 \pm 4.9$ & $12.8 \pm 3.9$ & \\
No. of days/month & $24.5 \pm 5.1$ & $23.8 \pm 4.7$ & \\
VAS & $81.2 \pm 18.7$ & $79.6 \pm 14.6$ & \\
Hospital anxiety and & $14.2 \pm 7.4$ & $15.9 \pm 8.1 *$ & $7.4 \pm 3.4$ \\
depression scores & & & \\
Anxiety score & $7.1 \pm 4.1$ & $7.9 \pm 3.9 * * *$ & $3.4 \pm 1.9$ \\
Depression score & $6.2 \pm 3.9$ & $8.0 \pm 4.2^{* * * *}$ & $4.1 \pm 2.2$ \\
\hline
\end{tabular}

aAll patients were asked to make one assessment of pain by means of a visual analogue scale (VAS) (0-100 score) during the 3 months of diary recording.

Average values during the monitoring period are presented.

Statistical significance : $* p<0.03$; $* * 0<0.05$; $* * * p<0.01$

water. After vigorous mixing, the upper aqueous phases were discarded to remove unreacted ethanolamine. The organic phases were washed twice with water, concentrated to dryness under a stream of $\mathrm{N}_{2}$, and the reaction products were reconstituted in methanol. Identity and chemical purity $(>98 \%)$ of the synthesized acylethanolamides (AEs) and $\left[{ }^{2} \mathrm{H}_{4}\right]$ AEs were determined by GC/MS.

These standards were added to three aliquots of CSF $(1.2 \mathrm{nmol}$ in $15 \mathrm{ml})$ to improve recovery and allow for quantification. After acetone precipitation of plasma proteins in CSF samples, the supernatants were collected and subjected to lipid extraction with methanol/chloroform. Enough of each solvent was added to reach a final ratio buffer/methanol/chloroform of 1:1:2 (v/v/v). The chloroform phases were recovered, evaporated to dryness under $\mathrm{N}_{2}$, and reconstituted in chloroform $(150 \mu \mathrm{l})$.

HPLC fractionations were performed on a HewlettPackard 1090 Liquid Chromatograph, equipped with a normal-phase Resolve Silica column $(3.9 \mathrm{~mm} \times 15 \mathrm{~cm}, 5 \mu \mathrm{m}$; Waters Associates, Milford, MA), eluted with a gradient of isopropyl alcohol (B) in $n$-hexane (A) $(100 \% \mathrm{~A}$ initial; $90 \%$ A, $10 \%$ B for $1 \mathrm{~min}$; $60 \%$ A, $40 \%$ B for $7 \mathrm{~min}, 50 \%$ A, $50 \%$ B for $12 \mathrm{~min}$ ) at a flow rate of $1.7 \mathrm{ml} / \mathrm{min}$. Under these conditions, all AEs were eluted from the HPLC column between 4.7 and $5.3 \mathrm{~min}$. The AE-containing fractions were collected in glass reaction vessels, dried under $\mathrm{N}_{2}$ and converted to trimethylethers by treatment with Bis(trimethylsilyl)trifluoroacetamide (BSTFA) for $30 \mathrm{~min}$ at room temperature. The trimethylsilylether (TMS) derivatives produced in this reaction were dried under $\mathrm{N}_{2}$, reconstituted in $n$-hexane and injected in the splitless mode into a Hewlett-Packard 5890 GC equipped with an HP-5MS capillary column $(30 \mathrm{~m}$; internal diameter, $0.25 \mathrm{~mm})$ and interfaced with a Hewlett-Packard 5972 MS.

Details on isotope dilution and GC/MS methods are reported elsewhere (Giuffrida and Piomelli, 1998).

The concentrations of analytes in the CSF samples were expressed as $\mathrm{pmol} / \mathrm{ml}$ and calculated in three separate determinations.
Lowest limits of detection were $0.16 \mathrm{pmol} / \mathrm{sample}$ for AEA, $0.10 \mathrm{pmol} / \mathrm{sample}$ for PEA and $0.20 \mathrm{pmol} / \mathrm{sample}$ for $2-\mathrm{AG}$. Accuracy and precision of the assays were obtained by measuring the recovery of known amounts of the three endocannabinoids in the presence of $0.5 \mathrm{nmol}$ of isotopelabeled standards in five independent determinations. Accuracy, expressed as the ratio between the actual and nominal values (\%) was 98,96 , and $95 \%$, respectively, for AEA, PEA, and 2-AG. Precision, expressed as percent coefficient of variation (CV), by dividing the standard deviation by the sample mean and multiplying the resulting value by 100 , was $3.9,4.2$, and $5.6 \%$.

Accuracy expressed as CV (\%) was 3.9, 4.5, and 5.9\% for AEA, PEA, and 2-AG, respectively.

CSF determination of CGRP. Five $\mathrm{ml}$ of CSF were collected according to the study protocol in polypropylene tubes containing EDTA $(1 \mathrm{mg} / \mathrm{ml})$ and kallikrein $(500 \mathrm{IU} / \mathrm{ml})$.

CGRP immunoreactivity was eluted with $60 \%$ acetonitrile in $0.1 \%$ trifluoroacetic acid in SEP-C18 columns activated with $0.1 \%$ trifluoroacetic acid and $60 \%$ acetonitrile in $0.1 \%$ trifluoroacetic acid. Eluates were associated with a centrifuge concentrator (Supervap PL-CC-180). Residues were dissolved in buffer and determined with RIA kits (Peninsula Laboratories, Belmont, CA). Neuropeptide data were expressed as pmol/l. Standards for the above substances were dissolved in $0.1 \mathrm{~mol} / \mathrm{l}$ phosphate buffer, $\mathrm{pH} 7.5$, containing $0.1 \%$ bovine albumin, $0.01 \%$ sodium azide and $500 \mathrm{IU} / \mathrm{ml}$ kallikrein. CGRP human antiserum was obtained from rabbit and was specific for the $\mathrm{C}$-terminal end for the neuropeptide. CGRP antiserum showed a crossreactivity with rat and chicken CGRP (100\%) but not with other neuropeptides. The intra- and interassay variabilities were 3 and $6 \%$, respectively. The detection limit of the assay was $<1 \mathrm{pmol} / \mathrm{l}$. Specificity data on CGRP were provided by Peninsula Laboratories.

CSF determination of nitrite. The oxidation products of $\mathrm{NO}$, nitrite and nitrate, were determined as total $\mathrm{NO}_{2}^{-}$after enzymatic reduction of nitrate to nitrite by fluorimetric HPLC analysis with precolumn hydralazine derivatization, as reported in one previous paper of our group (Gallai et al, 2003). Detection was achieved by fluorescence evaluation of the nitrite derivative at $360 \mathrm{~nm}$ emission and $228 \mathrm{~nm}$ excitation; quantification was performed by external standard calibration. The detection limit of the method was 0.3$0.5 \mathrm{pmol}$ of $\mathrm{NO}_{2}^{-}$in the column. The recovery of nitrite was calculated to range between 96 and $99 \%$. The reproducibility, including sample preparation and analysis, was specified with a CV of $6 \%$. The day-to-day variability of identical samples was $0.9 \%(\mathrm{CV})$. Data were expressed as $\mu \mathrm{mol} / \mathrm{l}$.

\section{Statistical Analysis}

Data from the patient and control groups were expressed as mean \pm SEM and compared using ANOVA, and Fisher's least significant difference (LSD) was also used to compare the main effect means in ANOVA. The correlation between variables was determined using Spearman's rank correlation test. All statistical tests were two-sided. $P$-values less than 0.05 were considered significant. 


\section{RESULTS}

Table 1 shows the details of the patient and control groups and for the patient groups also displays data relative to pain parameters and HADS.

No differences in pain parameters were found between the two patients groups, whereas patients with PCM+ $\mathrm{PAOH}$ had slightly significantly higher HADS scores. Nine patients in the $\mathrm{CM}$ patient group, 10 in the $\mathrm{PCM}+\mathrm{PAOH}$, and none of controls showed depression scale scores indicative of clinically relevant depression.

According to the modified DSM-IV substance dependence criteria, 12 patients $(80 \%)$ with $\mathrm{PCM}+\mathrm{PAOH}$ were classified as having substance dependence, whereas none of the patients with $\mathrm{CM}$ were classified as having substance dependence. The prevalence of DSM-IV dependence was highest among overusers of multiple classes or combination medication (100\%) than simple analgesics $(62.5 \%)$.

CSF concentrations of AEA was significantly lower both in patients with $\mathrm{CM}$ and in patients with $\mathrm{PCM}+\mathrm{PAOH}$ than in nonmigraine controls $(p<0.01)$. Conversely, significantly higher levels of PEA were found compared to control subjects $(p<0.02)$ without significant difference between the two patient groups (Table 2). Levels of 2-AG were below detection limits in both patient and control groups.

No significant correlation emerged between CSF levels of endogenous $\mathrm{CBs}$ and age in both $\mathrm{CM}$ and $\mathrm{PCM}+\mathrm{PAOH}$ patients and controls. This can be explained by the limited variance in the age of patients and control groups.

We also did not find any difference between CSF levels of the two CBs between CM patients classified as having medication dependence and those without when medication dependence was assumed as a categorical variable in ANOVA.

Besides the lack of any significant correlation between AEA and HADS scores, in particular depression scores, in all patient and control groups, significantly lower levels of AEA emerged in patients with a clinically significant depression (CM: $0.19 \pm 0.054$ and PCM + PAOH: $0.20 \pm 0.063$ compared with those without (CM: $0.23 \pm 0.069$ and PCM + PAOH: $\quad 0.24 \pm 0.058) \quad(p<0.02$ and $p<0.001)$. Patients without significant depression had in any case values significantly lower than those of control groups $(p<0.0005$ and $p<0.0003$, respectively). Conversely, there were no significant differences in CSF AEA levels between patients with and without concomitant depression in CM and $\mathrm{PCM}+\mathrm{PAOH}$ groups.

As shown in previous papers by our group (Gallai et al, 2003), significantly higher levels of CGRP and nitrites were found in patients with $\mathrm{CM}$, and this was also evident in the CSF of $\mathrm{PCM}+\mathrm{PAOH}$ patients with values of nitrites significantly greater than those found in CM patients (Table 2).

In both $\mathrm{CM}$ and $\mathrm{PCM}+\mathrm{PAOH}$ patient groups, CSF values of AEA, 2-AG, and PEA did not appear correlated with the duration of $\mathrm{CM}$ and the average intensity of pain during the monitoring period of 3 months, as measured by the visual analogue scale.

A negative correlation was found between AEA and CGRP levels in $\mathrm{CM}$ and $\mathrm{PCM}+\mathrm{PAOH}$ patients $(r=-0.59$, $p<0.018$; and $r=-0.65, p<0.007$; respectively) (Figure 1a and $b)$ and also emerged for PEA levels $v s$ CGRP in both patient groups $(r=-0.45, \quad p<0.002 ; \quad$ and $r=-0.57$, $p<0.003)$ (plots not shown).
Table 2 Levels of AEA, PEA, 2-AG, CGRP, and Nitrites (Mean $\pm \mathrm{SE}$ ) in Controls and $\mathrm{CM}$ and PCM+PAOH Patient Groups

\begin{tabular}{lccc}
\hline & Controls & CM & PCM+PAOH \\
\hline AEA $(\mathrm{pmol} / \mathrm{ml})$ & $0.39 \pm 0.09$ & $0.21 \pm 0.060^{*}$ & $0.22 \pm 0.05^{*}$ \\
PEA $(\mathrm{pmol} / \mathrm{ml})$ & $4.91 \pm 0.47$ & $6.21 \pm 0.59^{\S}$ & $6.23 \pm 0.52^{\$ \S}$ \\
CGRP $(\mathrm{pmol} / \mathrm{l})$ & $29.37 \pm 4.67$ & $44.16 \pm 4.63^{\wedge}$ & $43.96 \pm 5.22^{\wedge}$ \\
Nitrites $(\mu \mathrm{mol} / \mathrm{l})$ & $13.66 \pm 2.89$ & $24.51 \pm 4.44^{\#}$ & $31.42 \pm 6.93^{\# \# \circ}$ \\
\hline
\end{tabular}

Statistical significance vs controls: $A E A=* p<0.0001 ; P E A={ }^{\S} p<0.0002$;

${ }^{\$ \S_{p}} p<0.0004 ; \mathrm{CGRP}={ }^{\wedge} p<0.0005 ;{ }^{\wedge} p<0.000$ I; Nitrites $={ }^{\#} p<0.0003$;

$\#$ \#\# $<0.001$.

Statistical significance vs CM: Nitrites $={ }^{\circ} p<0.02$

A similar trend toward a negative correlation was observed between the two endogenous $\mathrm{CBs}$, AEA and PEA, and nitrite levels in the CSF of both CM and PCM + $\mathrm{PAOH}$ patient groups $(r=-0.63, p<0.01 ; r=-0.77$, $p<0.006$; Figure 2a and $\mathrm{b}$, respectively; PEA plots not shown).

\section{DISCUSSION}

Migraine has been suggested to have an underlying CECD (Russo, 2004).

Current anecdotal references continue to refer to the putative efficacy of AEA for migraine, but biochemical studies providing a scientific basis for such treatment are lacking (Russo, 1998). In the present study, reduced AEA levels in the CSF of CM patients support the hypothesis of the failure of this endogenous $\mathrm{CB}$ system in $\mathrm{CM}$, which seems to be related to increased CGRP and NO production in this pathological condition. This finding might be due to a failure of the inhibitory role of the endocannabinoid AEA on the trigeminovascular system activation via $\mathrm{CB}(1)$ receptors localized on fibers in the spinal trigeminal tract and spinal trigeminal nucleus caudalis. This inhibitory effect has been demonstrated in experimental settings where AEA was able to inhibit dural blood vessel dilation due either to electrical stimulation or to CGRP, capsaicin, or NO application. This effect was reversed by the $\mathrm{CB}(1)$ receptor antagonist AM251 (Akerman et al, 2004a).

The reduction in CSF levels of AEA does not seem specific for CM because it was also evident in the CSF of patients with $\mathrm{PCM}+\mathrm{PAOH}$, but appears to be related to chronic head pain per se.

In contrast to the reduction of AEA, significantly higher levels of PEA were found in both patient groups compared to nonmigraineur controls. It can hypothesized that increased PEA levels represent a compensatory response to reduced levels of AEA, the latter due probably to an acceleration of its metabolism in $\mathrm{CM}$ patients and $\mathrm{PCM}+\mathrm{PAOH}$. Experimental findings support in fact the role of PEA and PEA derivatives in the inhibition of FAAH-catalyzed hydrolysis of AEA, which can result in a potentiation of AEA action (Vandevoorde et al, 2003). Based on these findings, increased levels of PEA can be interpreted as a physiological mechanism counteracting accelerated AEA catabolism in these pathological chronic pain conditions. 
$\mathrm{CM}$

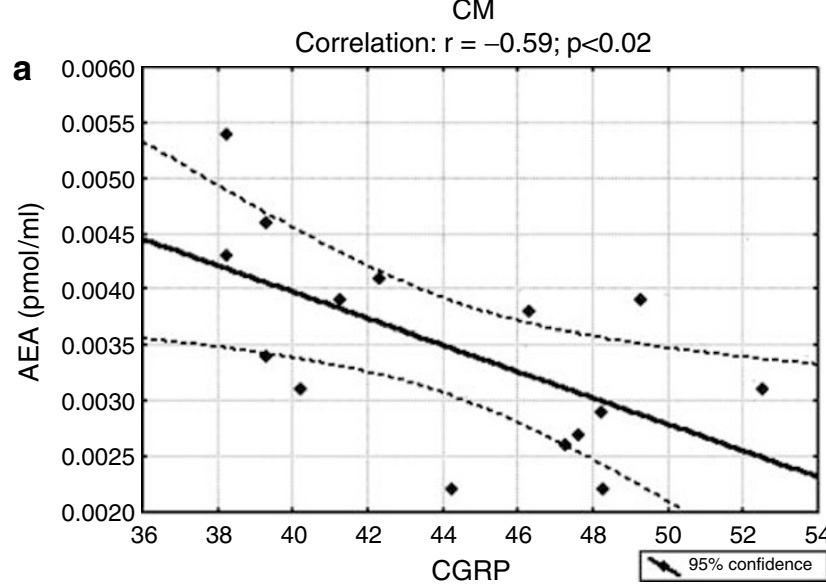

$\mathrm{PCM}+\mathrm{PAOH}$

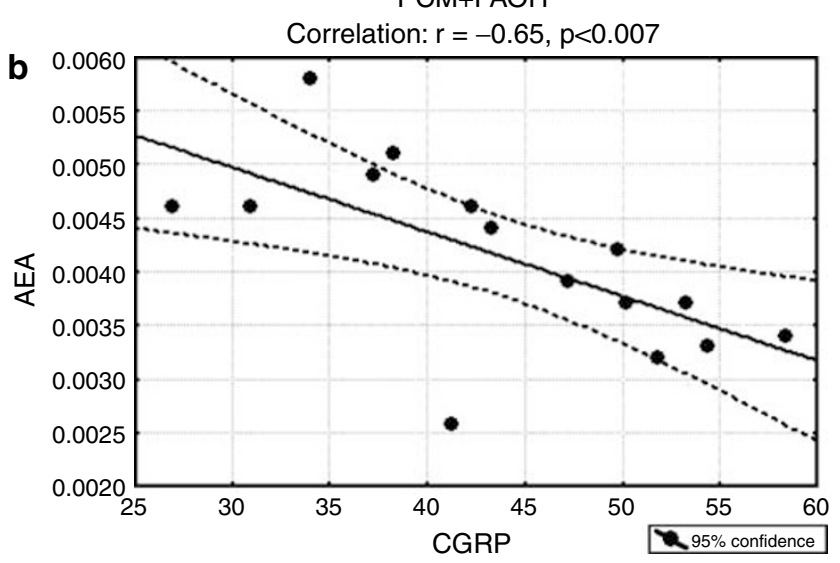

Figure I ( $a$ and $b$ ) Plot of the levels of AEA vs CGRP, expressed as $\mathrm{pmol} / \mathrm{ml}$ and $\mathrm{pmol} / \mathrm{l}$, in patients with CM (a) and in patients with $\mathrm{PCM}+\mathrm{PAOH}(\mathrm{b})$.

Based on our findings, it can be hypothesized that the failure of the inhibitory role of AEA can contribute to maintaining central sensitization in chronic head pain, and represents a further mechanism which intervenes in increasing the release of the sensory neuropeptide CGRP and NO production, together with nerve growth factor (NGF) and brain-derived neurotrophic factor (BDNF) release via glutamatergic transmission (Sarchielli et al, 2001, 2002).

It has been demonstrated that endocannabinoids, in particular AEA, positively influence serotonin levels in the brain of experimental animals, supporting its putative role in mood regulation, which pointed to FAAH as a previously uncharacterized target for antidepressant drugs (Gobbi et al, 2005).

As migraine has been related to a serotonergic dysfunction, which is more accentuated in chronic forms, including those with analgesic overuse (Srikiatkhachorn et al, 1998; Sarchielli et al, 1999), it is plausible that lower levels of AEA can reflect lower levels of this monoamine in both $\mathrm{CM}$ and $\mathrm{PCM}+\mathrm{PAOH}$ patient groups.

The chemical theory of depression postulates, at the basis of its debilitating and often chronic symptoms, a perturbation of monoamine transmission and depletion of these neurotransmitters. This is strongly supported by the
$\mathrm{CM}$

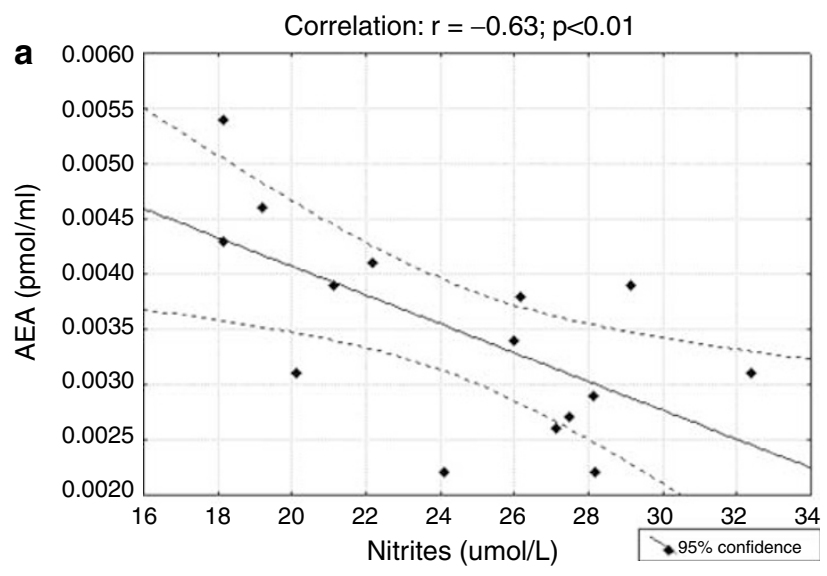

$\mathrm{PCM}+\mathrm{PAOH}$

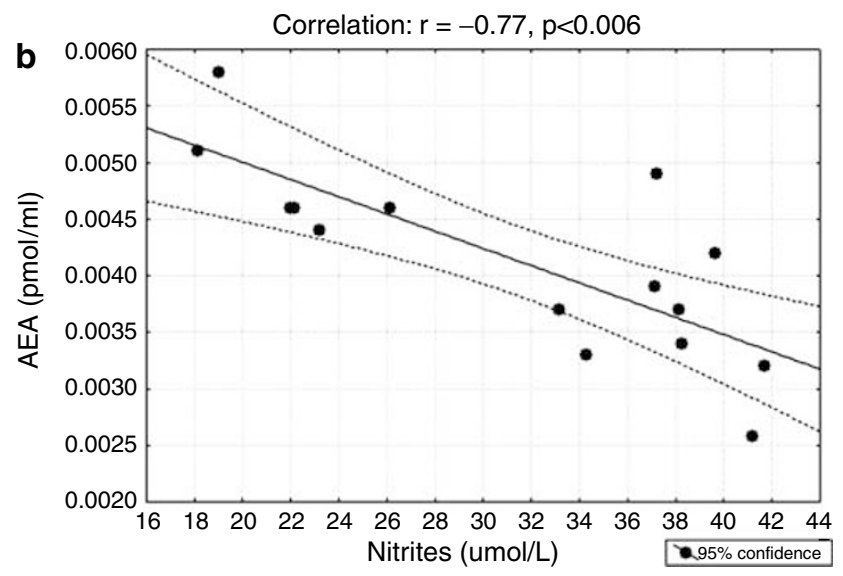

Figure 2 ( $a$ and $b$ ) Plot of the levels of AEA vs nitrite, expressed as $\mathrm{pmol} / \mathrm{ml}$ and $\mu \mathrm{mol} / \mathrm{l}$, in patients with $\mathrm{CM}$ (a) and in patients with $\mathrm{PCM}+\mathrm{PAOH}(\mathrm{b})$.

effectiveness of monoamine oxidase inhibitors (MAOIs), tricyclic antidepressants (TCAs), and more recently of serotonin reuptake inhibitors (SSRIs) and serotonin/ norepinephrine reuptake inhibitors (SNRIs), which elevate levels of monoamines, by preventing their metabolism and blocking their reuptake, the latter two acting more selectively on the serotonin system (Schechter et al, 2005). The majority of these drugs are included among preventive treatment of migraine based on the assumption of a serotonin system derangement in migraine, particularly in the chronic forms.

Although we did not measure serotonin levels in the CSF of subjects of all groups and could not relate these levels to AEA, we found that patients with scores indicative of clinically relevant depression in $\mathrm{CM}$ and $\mathrm{PCM}+\mathrm{PAOH}$ groups showed lower levels of AEA than those without. Patients without clinically significant depression had, however, CSF values of AEA significantly reduced than those of controls in both patient groups.

These findings thus support not only chronic pain as being characterized by a deficiency of this endocannabinoid but also the contribution of depression comorbidity to AEA reduction in the CSF of both $\mathrm{CM}$ and $\mathrm{PCM}+\mathrm{PAOH}$ patients.

Whether this reduction is also peculiar for other chronic pain conditions should be clarified by future research 
investigating the levels of endogenous CBs in other, similar conditions, such as fibromyalgia or IBS.

The findings of the present study offer some speculations on the pathophysiologic aspects of chronic pain in general, and chronic head pain in particular. Chronic head pain, like other chronic pain syndromes, is characterized by altered neuronal excitability in the pain matrix (van der Stelt and Di Marzo, 2003). In these conditions, neuroplastic changes and reorganization of neuronal pathways take place at several levels in the spinal cord, in thalamic nuclei, and in cortical and subcortical (limbic) areas integrating pain threshold, intensity, and affective components. The endogenous CB system plays a central role in the extinction of aversive memories, including that related to pain, by facilitating their selective inhibitory effects on GABAergic networks at different levels in the pain matrix (Marsicano et al, 2002). Reduction in endocannabinoids can therefore result in a failure of discharge activity of interneurons, controlling neurons conveying nociceptive information and counteracting long-term changes in the pain matrix following nociceptor activation (Walker and Huang, 2002). This may explain not only the transition of acute pain signaling to chronic pain states, including chronic head pain, but also their maintenance.

Moreover, it cannot be excluded that changes in CSF levels of AEA and PEA can reflect migraine, since both CM and $\mathrm{PCM}+\mathrm{PAOH}$ share the same biological substrate. To clarify the role for endocannabinoids in chronic head pain would require a further primary chronic headache study.

It could be wise to study endocannabinoids in the CSF of patients with chronic tension-type headache. This could discriminate whether endocannabinoid system changes are a response unique in some way to migraine or can be extended to other chronic head pain conditions. This issue will be the aim of future research of our group.

It has been recently suggested that the endocannabinoid system might be a component of the brain reward circuitry and thus play a role not only in $\mathrm{CB}$ tolerance/dependence but also in dependence/withdrawal to other drugs of abuse (Di Marzo et al, 2000; Gonzalez et al, 2003; Centonze et al, 2004). Changes in endocannabinoid ligands and their receptors have been shown in different brain regions, with particular attention to those areas related to reinforcement processes, during dependence on powerful addictive drugs. There is also a growing body of evidence supporting the potential intervention of the endocannabinoid system in the motivational and dopamine-releasing effects of several drugs of abuse and dependence (Parolaro et al, 2005; Calabresi and Cupini, 2005).

It remains to be established if similar mechanisms are activated in the case of analgesic overuse involved in migraine chronicity as suggested by our findings.

In our study we did not find any significant differences in CSF AEA levels between the two patient groups with and without medication overuse, supporting the involvement of AEA reduction in chronic head pain independently of its relation to drug abuse and dependence.

Other aspects related to this dysfunction and potential failure of $\mathrm{CB}(1)$ mediated signaling also need to be clarified.

Some experimental evidence allows, in fact, to hypothesize other targets for AEA or analogs other than $\mathrm{CB}(1)$. In an in vitro setting, AEA has been demonstrated to activate
TRPV1, the nonselective cation channel that belongs to the large family of TRP ion channels, activated by the pungent ingredient of hot chilli peppers, capsaicin (Akerman et al, $2004 \mathrm{~b})$. They are expressed in some nociceptor efferent neurons, where they act as a molecular sensor of noxious heat and low $\mathrm{pH}$. The activation of TRPV1 receptors in trigeminovascular system activation via AEA promotes CGRP release and causes vasodilation independent of any action at the $\mathrm{CB}(1)$ receptor, and therefore moderates an opposite effect of that attributed to endocannabinoids through metabotropic receptors.

Whether and how the above mechanisms play a pivotal role in chronic pain and $\mathrm{CM}$, in particular, remains to be established in the search for new therapeutic strategies in migraine. In this regard, other endogenous substances have been discovered, which need to be investigated in future research: the endovanilloids, which are defined as endogenous ligands of the TRPV1 protein. Other than AEA, they include some of its congeners, such as unsaturated $\mathrm{N}$-acyldopamines and lipoxygenase products of arachidonic acid (Van der Stelt and Di Marzo, 2004). Research in their regard is warranted.

\section{ACKNOWLEDGEMENTS}

We express our gratitude to John A Toomey for editing the English and Marisa M Morson for technical assistance.

\section{CONFLICT OF INTEREST}

We have no financial or nonfinancial conflict of interests to declare.

\section{REFERENCES}

Akerman S, Kaube H, Goadsby PJ (2004a). Anandamide is able to inhibit trigeminal neurons using an in vivo model of trigeminovascular-mediated nociception. J Pharmacol Exp Ther 309: 56-63.

Akerman S, Kaube H, Goadsby PJ (2004b). Anandamide acts as a vasodilator of dural blood vessels in vivo by activating TRPV1 receptors. Br J Pharmacol 142: 1354-1360.

American Psychiatric Association (1994). Diagnostic and Statistical Manual of Mental Disorders, 4 th edn. American Psychiatric Association: Washington, DC.

Breivogel CS, Walker JM, Huang SM, Roy MB, Childers SR (2004). Cannabinoid signaling in rat cerebellar granule cells: G-protein activation, inhibition of glutamate release and endogenous cannabinoids. Neuropharmacology 47: 81-91.

Calabresi P, Cupini LM (2005). Medication-overuse headache: similarities with drug addiction. Trends Pharmacol Sci 26: 62-68.

Calignano A, La Rana G, Giuffrida A, Piomelli D (1998). Control of pain initiation by endogenous cannabinoids. Nature 394: 277-281.

Calignano A, La Rana G, Piomelli D (2001). Antinociceptive activity of the endogenous fatty acid amide, palmitylethanolamide. Eur J Pharmacol 419: 191-198.

Centonze D, Battista N, Rossi S, Mercuri NB, Finazzi-Agro A, Bernardi $\mathrm{G}$ et al (2004). A critical interaction between dopamine D2 receptors and endocannabinoids mediates the effects of cocaine on striatal gabaergic transmission. Neuropsychopharmacology 29: 1488-1497.

Cheer JF, Cadogan AK, Marsden CA, Fone KC, Kendall DA (1999). Modification of 5-HT2 receptor mediated behaviour in the rat by 
oleamide and the role of cannabinoid receptors. Neuropharmacology 38: 533-541.

Cravatt BF, Lichtman AH (2004). The endogenous cannabinoid system and its role in nociceptive behavior. J Neurobiol 61: 149-160.

Di Marzo V, Berrendero F, Bisogno T, Gonzalez S, Cavaliere P, Romero J et al (2000). Enhancement of anandamide formation in the limbic forebrain and reduction of endocannabinoid contents in the striatum of delta9-tetrahydrocannabinol-tolerant rats. J Neurochem 74: 1627-1635.

Di Marzo V, Blumberg PM, Szallasi A (2002a). Endovanilloid signaling in pain. Curr Opin Neurobiol 12: 372-379.

Di Marzo V, De Petrocellis L, Fezza F, Ligresti A, Bisogno T (2002b). Anandamide receptors. Prostaglandins Leukot Essent Fatty Acids 66: 377-391.

Drysdale AJ, Platt B (2003). Cannabinoids: mechanisms and therapeutic applications in the CNS. Curr Med Chem 10: 2719-2732.

Freund TF, Katona I, Piomelli D (2003). Role of endogenous cannabinoids in synaptic signaling. Physiol Rev 83: 1017-1066.

Fride E (2002). Endocannabinoids in the central nervous system-an overview. Prostaglandins Leukot Essent Fatty Acids 66: 221-233.

Fuh J-L, Wang S-J, Lu S-R, Juang K-D (2005). Does medication overuse headache represent a behavior of dependence? Pain 119: 49-55. (E-pub November 17, 2005).

Gallai V, Alberti A, Gallai B, Coppola F, Floridi A, Sarchielli P (2003). Glutamate and nitric oxide pathway in chronic daily headache: evidence from cerebrospinal fluid. Cephalalgia 23: 166-174.

Giuffrida A, Leweke FM, Gerth CW, Schreiber D, Koethe D, Faulhaber $\mathrm{J}$ et al (2004). Cerebrospinal anandamide levels are elevated in acute schizophrenia and are inversely correlated with psychotic symptoms. Neuropsychopharmacology 29: 2108-2114.

Giuffrida A, Piomelli D (1998). Isotope dilution GC/MS determination of anandamide and other fatty acylethanolamides in rat blood plasma. FEBS Lett 422: 373-376.

Gobbi G, Bambico FR, Mangieri R, Bortolato M, Campolongo P, Solinas $M$ et al (2005). Antidepressant-like activity and modulation of brain monoaminergic transmission by blockade of anandamide hydrolysis. Proc Natl Acad Sci USA 102: 18620-18625. (E-pub December 13, 2005. Erratum in: Proc Natl Acad Sci USA 2006; 103: 2465).

Gonzalez S, Schmid PC, Fernandez-Ruiz J, Krebsbach R, Schmid HH, Ramos JA (2003). Region-dependent changes in endocannabinoid transmission in the brain of morphine-dependent rats. Addict Biol 8: 159-166.

Grotenhermen F (2004). Pharmacology of cannabinoids. Neuro Endocrinol Lett 25: 14-23.

Gubellini P, Picconi B, Bari M, Battista N, Calabresi P, Centonze D et al (2002). Experimental parkinsonism alters endocannabinoid degradation: implications for striatal glutamatergic transmission. J Neurosi 22: 6900-6907.

Headache Classification Subcommittee of the International Headache Society (2004). The International Classification of Headache Disorders, 2nd edn. Cephalalgia 24(Suppl 1): 1-160.

Hohmann AG (2002). Spinal and peripheral mechanisms of cannabinoid antinociception: behavioral, neurophysiological and neuroanatomical perspectives. Chem Phys Lipids 121: 173-190.

Howlett AC, Breivogel CS, Childers SR, Deadwyler SA, Hampson RE, Porrino LJ (2004). Cannabinoid physiology and pharmacology: 30 years of progress. Neuropharmacology 47(Suppl 1): 345-358.

Kimura T, Ohta T, Watanabe K, Yoshimura H, Yamamoto I (1998). Anandamide, an endogenous cannabinoid receptor ligand, also interacts with 5-hydroxytryptamine (5-HT) receptor. Biol Pharm Bull 21: 224-226.
Leweke FM, Giuffrida A, Wurster U, Emrich HM, Piomelli D (1999). Elevated endogenous cannabinoids in schizophrenia. Neuroreport 10: 1665-1669.

Marsicano G, Wotjak CT, Azad SC, Bisogno T, Rammes G, Cascio MG et al (2002). The endogenous cannabinoid system controls extinction of aversive memories. Nature 418: 530-534.

Mbvundula EC, Rainsford KD, Bunning RA (2004). Cannabinoids in pain and inflammation. Inflammopharmacology 12: 99-114.

Melis M, Pistis M, Perra S, Muntoni AL, Pillolla G, Gessa GL (2004). Endocannabinoids mediate presynaptic inhibition of glutamatergic transmission in rat ventral tegmental area dopamine neurons through activation of $\mathrm{CB} 1$ receptors. $J$ Neurosci 24: 53-62.

Parolaro D, Vigano D, Rubino T (2005). Endocannabinoids and drug dependence. Curr Drug Targets CNS Neurol Disord 4: 643-655.

Pertwee RG (2001). Cannabinoid receptors and pain. Prog Neurobiol 63: 569-611.

Ross RA (2003). Anandamide and vanilloid TRPV1 receptors. $\mathrm{Br} J$ Pharmacol 140: 790-801.

Russo E (1998). Cannabis for migraine treatment: the once and future prescription? An historical and scientific review. Pain 76: 3-8.

Russo EB (2004). Clinical endocannabinoid deficiency (CECD): can this concept explain therapeutic benefits of cannabis in migraine, fibromyalgia, irritable bowel syndrome and other treatment-resistant conditions? Neuro Endocrinol Lett 25: 31-39.

Sarchielli P, Alberti A, Floridi A, Gallai V (2001). Levels of nerve growth factor in cerebrospinal fluid of chronic daily headache patients. Neurology 57: 132-134.

Sarchielli P, Alberti A, Gallai B, Coppola F, Baldi A, Gallai V (2002). Brain-derived neurotrophic factor in cerebrospinal fluid of patients with chronic daily headache: relationship with nerve growth factor and glutamate levels. J Headache Pain 3: 129-135.

Sarchielli P, Alberti A, Russo S, Codini M, Panico R, Floridi A et al (1999). Nitric oxide pathway, $\mathrm{Ca} 2+$, and serotonin content in platelets from patients suffering from chronic daily headache. Cephalalgia 19: 810-816.

Schechter LE, Ring RH, Beyer CE, Hughes ZA, Khawaja X, Malberg $\mathrm{JE}$ et al (2005). Innovative approaches for the development of antidepressant drugs: current and future strategies. NeuroRx 2 : 590-611.

Srikiatkhachorn A, Maneesri S, Govitrapong P, Kasantikul V (1998). Derangement of serotonin system in migrainous patients with analgesic abuse headache: clues from platelets. Headache 38: $43-49$.

Szallasi A (2002). Vanilloid (capsaicin) receptors in health and disease. Am J Clin Pathol 118: 110-121.

van der Stelt M, Di Marzo V (2003). The endocannabinoid system in the basal ganglia and in the mesolimbic reward system: implications for neurological and psychiatric disorders. Eur $J$ Pharmacol 480: 133-150.

van Der Stelt M, Di Marzo V (2004). Endovanilloids. Putative endogenous ligands of transient receptor potential vanilloid 1 channels. Eur J Biochem 271: 1827-1834.

Vandevoorde S, Jonsson KO, Fowler CJ, Lambert DM (2003). Modifications of the ethanolamine head in $\mathrm{N}$-palmitoylethanolamine: synthesis and evaluation of new agents interfering with the metabolism of anandamide. J Med Chem 46: 1440-1448.

Vaughan CW, Connor M, Bagley EE, Christie MJ (2000). Actions of cannabinoids on membrane properties and synaptic transmission in rat periaqueductal gray neurons in vitro. Mol Pharmacol 57: 288-295.

Walker JM, Huang SM (2002). Cannabinoid analgesia. Pharmacol Ther 95: 127-135. 